\title{
EXPERIMENTAL PERFORMANCE ANALYSIS OF BIPLANE VAWT CONFIGURATIONS
}

\author{
Z. S. Oulhaci' O. Imine' ${ }^{1}$ O. Ladjedel' $\quad$ T. Yahiaoui' L. Adjlout ${ }^{2}$ Ondřej Sikula ${ }^{3^{*}}$ \\ ${ }^{1}$ Laboratoire d'aéronautique et systèmes propulsive,Département de Génie Mécanique, \\ Mechanical Engineering Faculty, USTO Oran, Algeria \\ 'Laboratoire d'aérohydrodynamique naval Département de génie maritime, \\ Mechanical Engineering Faculty, USTO Oran, Algeria \\ ${ }^{3}$ Brno University of Technology, Faculty of Civil Engineering, Brno Czech Republic
}

This paper aim to develop a new Darrieus wind turbine configurations based on the concept of biplane blades in order to improve the performances of the machine. The performances of the new design were investigated numerically and experimentally. Firstly a 2-D steady numerical simulation of an isolated two blades is carried out to exhibit the aerodynamic performance behavior. Secondly experiences are made on different Darrieus wind turbine by considering the biplane blade models. The experiments are carried out in wind tunnel by testing firstly: two, three and four blades Darrieus wind turbine as well as the biplane new configurations. The results of static torque and rotational speeds versus a wind velocity are presented. The obtained results corresponding to the new machines present a great improvement in the performances.

Key words: CFD simulation, Wind tunnel, Biplane blades configuration, Performance, Darrieus wind turbine

\section{NOMENCLATURE}

VAWT vertical axis wind turbine

$H \quad$ height of turbine [cm]

$C$ blade chord [cm]

$R \quad$ turbine radius [cm]

$Q \quad$ overall torque [N.m]

$C L \quad$ lift coefficient [-]

$C D \quad$ drag coefficient [-]

$U_{\infty} \quad$ wind velocity $[\mathrm{m} / \mathrm{s}]$

$\varpi \quad$ rotational speed of the machine [rpm]

a incidence angle [ $\left.{ }^{\circ}\right]$

\section{INTRODUCTION}

In order to reduce the cost and dependence on energy, as much as for ecological reasons, several countries have committed to reduce their emissions of greenhouse gases. This is why these countries search to limit their consumption of oil and nuclear energy, hence the interest of developing a renewable and environmentally friendly source of energy such as wind power. Wind energy can provide solutions for global climate change and the energy crisis. There are two types of wind turbines: HAWT (horizontal axis wind turbine) and the VAWT (vertical axis wind turbine) based on their axis of rotation. HAWT are more adapted for large scale energy generation But for small-scale and micro-scale power generation the VAWT are more adapted, easy to install and omni-directional [01]. In general wind energy is related to the HAWT, while the VAWT are neglected. Hence this paper focuses on study of VAWTs type Darrieus turbine to shed light on this type of machine. By the use of CFD and experimental measurements, the understanding of
VAWTs can be improved. In order to determine the rotor power curve and based on numerical simulations, a new straight bladed VAWT performance prediction model was proposed by Marco castelli et al. [02]. As a mean to reduce the torque variation during the revolution of a vertical-axis wind turbine (VAWT). Marco Raciti et al. [03] increase the blade number. they concluded that for lower angular speeds, larger number of blades allow to reach the maximum power coefficient. A combined experimental and computational study into the aerodynamics and performance of a small scale VAWT are presented by Robert Howell et al. [04]. Taher $G$ et al. [5] tested the influence of changing the design parameters, number of blades and blade chord length on the efficiency of straight Darrieus wind turbine. The effect of the modifications made on the NACA-0015 profile used in VAWTs is investigated by Md Farhad Ismail et al. [06]. A CFD procedure with different airfoil shapes is done by M.H.Mohamed et al. [07] on Darrieus turbine to assess its performance. Arti tirkey et al. [08] also studied the effect of blade profile, blade number, surface roughness of blade, aspect ratio and Reynolds number on the performance of VAWT, by performing a numerical analysis. Besides the study of the effect of blades number on the performance of Darrieus wind turbine Payam Sabaeifard et al. [09] studied also the effect of other parameters as airfoil types and turbine solidity through a computational and experimental study into the aerodynamics and performance of small scale Darrieus wind turbine. Taher $G$ et al. [10] the effect of barrier placed in front of rotor on the Darrieus performance is analyzed numerically; this barrier has been designed to increase the performance of the Darrieus wind rotor. Danao et al. [11] realized nu- 
merical simulations on a small scale VAWT to study the effect of steady and unsteady wind on the performance of the machine. By means of Richardson extrapolation method, grid convergence index method, and the fitting method, mesh independent solution, was recently investigated for a 2-D VAWT by Almohammadi et al. [12]. Nobile et al. [13] carried out a 2-D CFD investigation of an augmented VAWT that involved omnidirectional stator located around the VAWT. They reported an increase of around 30 to $35 \%$ in torque and power coefficients. M. Elkhoury et al. [14] realized a combined experimental and numerical investigation on a micro vertical-axis wind turbine (VAWT) with variable-pitch to assess the effect of wind speed, airfoil shape, and variable-pitch mechanism on the performance of turbine. The performances of 4-bladed $\mathrm{H}$-Darrieus rotor including different symmetrical and unsymmetrical NACA 4 digit profiles with varying conditions of rotor radius, pitch angle etc was investigated by El-Samanoudy et al. [15]. To study the performance of the rotor, two different rotor solidities were investigated 0.75 and 1.5 respectively, the obtained results show that for the first solidity $(0.75)$ the maximum power coefficient reported is about $7 \%$; but for this later still inferior for the 2 or 3 blade designs. To solve the problem of self-starting a three-bladed H-type Darrieus rotor equipped with unsymmetrical $\mathrm{s} 1210$ blades was experimented by M.A. Singh et al [16]. Many rotor solidities have been tested for the range of [0.8 - 1.2] and this at diverse azimuthal positions. The results showed that for all solidities conditions a high increases in positive static torque coefficients (STC) at all rotor angles was observed for the new rotor and for a comparison with the classical existing rotors (using unsymmetrical or symmetrical blade) the STC for the new designs is superior about four times. A.M.CISMILIANU et al [17] presented a new configuration of Darrieus turbine based on the rules of biplane airplanes and consisting to add a second set of blades. The new biplane turbine was made by keeping the radius and adding in the interior a row of three blades with similar airfoil and chord, but staggered with respect to baseline blades with 0.5 chord in a tangential direction and the radial distance between the two blades is about 0.625 chord. Through their numerical and experimental investigations, they concluded that in urban areas, the biplane solution is superior to the classic solution, i.e., of $\mathrm{H}$ - Darrieus type. According to the results of the study of ref [17], the present paper show an experimental investigation carried out on Darrieus wind turbine biplane configurations. The purpose of this study is to investigate the effect of tangential displacement on aerodynamic performances of biplane configurations. In this context, the study focused on three cases namely: 0.5 chord upstream, 0 chord (biplane blades without displacement) and 0.5 chord downstream. This later configuration is called in ref [17] positive stagger configuration. It is noticed that the radial distance between the biplane blades is maintained constant with 1 chord value. A comparative study is also proposed in this work between the perfor- mances of the new suggested design and the classical Darrieus wind turbine.

\section{TURBINE PARAMETERS}

The analysis of Darrieus wind turbine operation is easy demonstrated by considering a two-dimensional aspect as shown in Figure 1. The upstream far-field flow velocity is designated by $U_{\infty}$.

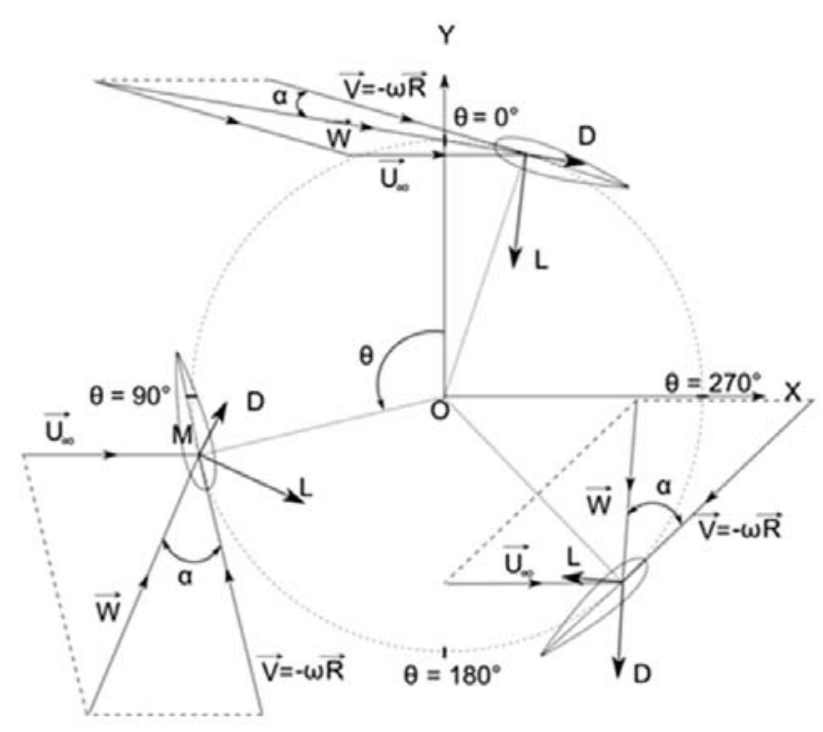

Figure 1: Forces and velocities triangles in a Darrieus turbine

During rotation, the attack angle is varying from positive to negative values. The relative velocity, $W$, and the attack angle, $\alpha$ are given by:

$$
\begin{aligned}
W & =U_{\infty} \sqrt{(\lambda+\cos \theta)^{2}+(\sin \theta)^{2}} \\
\alpha & =\arctan \left(\frac{\sin \theta}{\lambda+\cos \theta}\right)
\end{aligned}
$$

The fluid forces resulting from the fluid action on the blade is projected respectively in the $\overrightarrow{\mathrm{W}}$ and perpendicular to $\overrightarrow{\mathrm{W}}$ directions, thus, obtaining a drag force $D$ and a lift force $L$. These forces are normalized introducing the lift and drag coefficients as follows:

$$
\begin{aligned}
& C_{l}=F_{L} / \frac{1}{2} \rho C H W^{2} \\
& C_{D}=F_{D} / \frac{1}{2} \rho C H W^{2}
\end{aligned}
$$

The tangential coefficient is formulated by the following equation:

$$
C_{T}=C_{L} \sin \alpha-C_{D} \cos \alpha
$$

According to Equation (2), Figure 2 illustrates the inci) dence angle $\alpha$ versus the azimuthal angle $\theta$ for several tip speed ratios $\lambda$. 


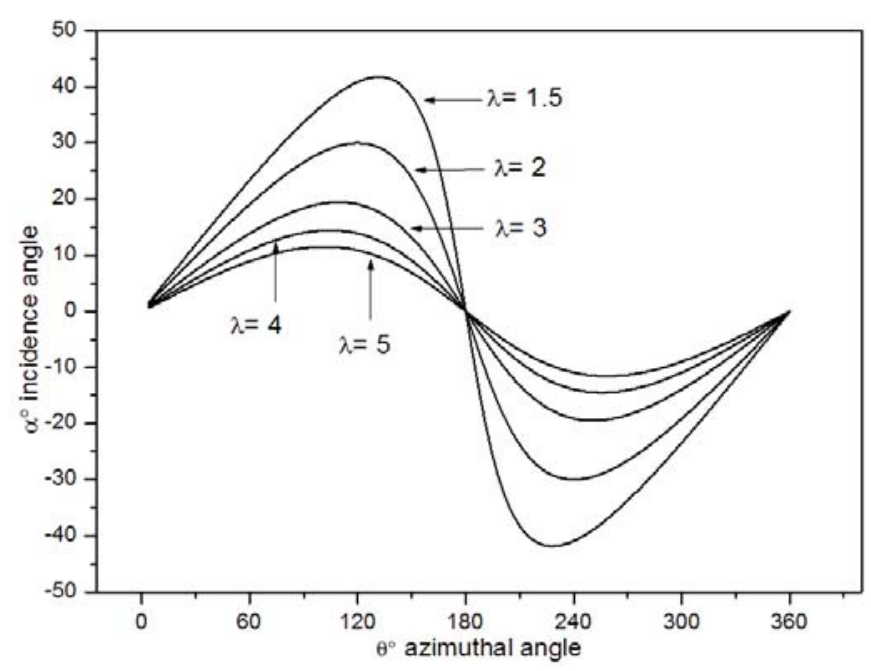

Figure 2: Variation of the angle of incidence according to the azimuth angle

\section{NUMERICAL MODELING}

In this section a preliminary numerical study is carried out to exhibit the behavior of aerodynamic coefficients related to monoplane and biplane configurations. Finite-Volume Method (FVM) is applied on unstructured grids is to calculate the 2-D steady incompressible Navier-Stokers equations using Spalart Almaras model. For

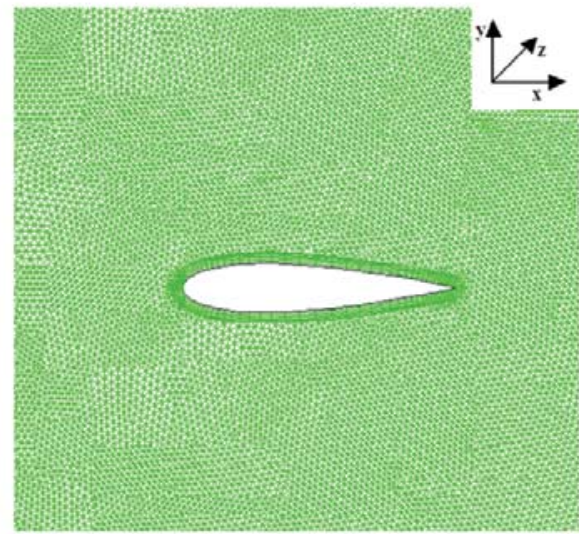

a)

One blade

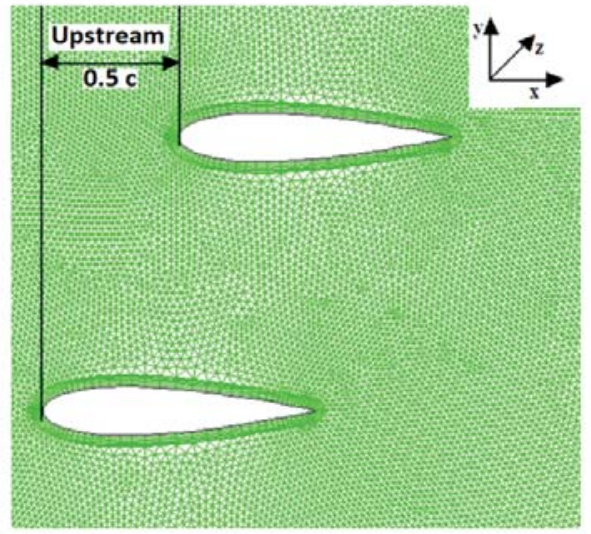

c) Two blades 0.5C Upstream shift momentum discretization a second-order Upwind differencing scheme is employed. To deal with the pressure-velocity coupling between the momentum and continuity equations, the Pressure Implicit method with Splitting of Operators (SIMPLE) algorithm is used. The calculations are experienced by varying the incidence angle from $0^{\circ}$ to $30^{\circ}$ which corresponds in the case of Darrieus wind turbine to the tip speed ratios equal to $\lambda=2$. Four cases are carried out in different arrangements as shown in Figure 3.

The geometry of the two-dimensional domain representing a calculated domain is shown in figure 4 . At the inlet boundary, a velocity inlet with a value of $18 \mathrm{~m} / \mathrm{s}$ is imposed as inflow boundary condition. A pressure outlet is used at the outlet boundary. The profiles surfaces are also treated as no-slip surfaces using wall conditions. The lateral surfaces are treated as symmetry boundary condition.

The obtained results of this numerical investigation are shown in Figures 5, 6, 7. It is noticed that the aerodynamic coefficients of all tested configurations were determined by dividing the aerodynamic forces by the same quantity. From the exam of these results, the biplane configurations reveal an interesting mechanical energy potential in VAWT field.

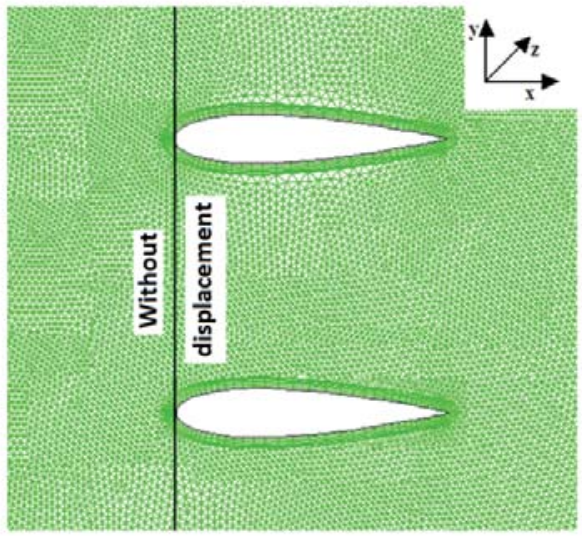

b) Two blades without displacement

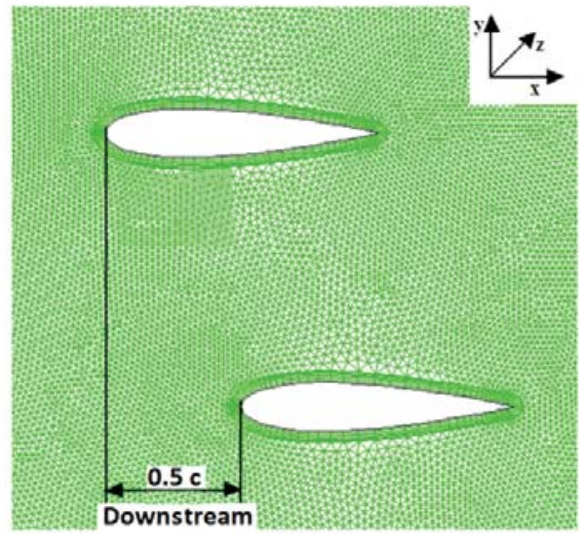

d) Two blades 0.5C Downstream shift

Figure 3: Tested cases of isolated blades 


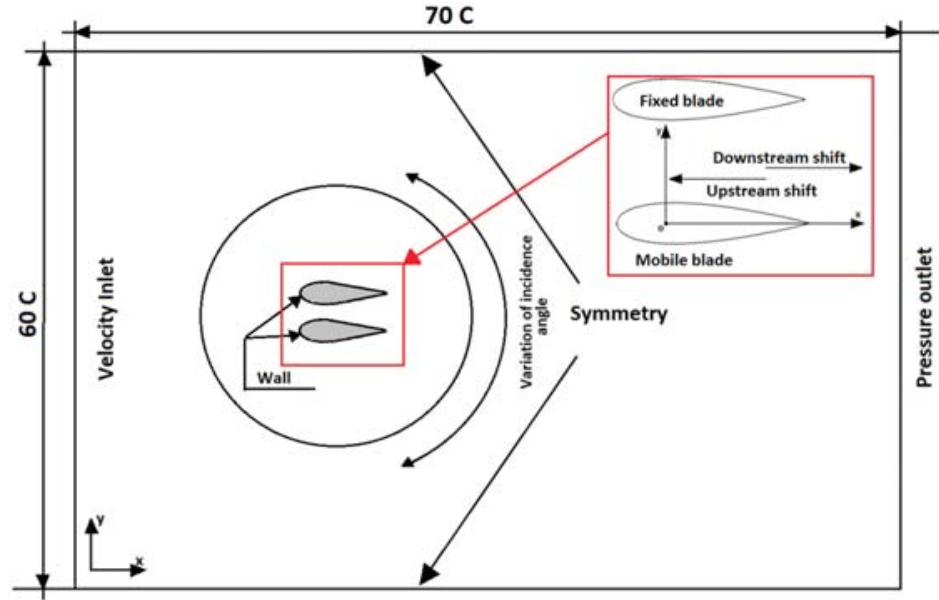

Figure 4: Geometry of the tow-dimensional domain

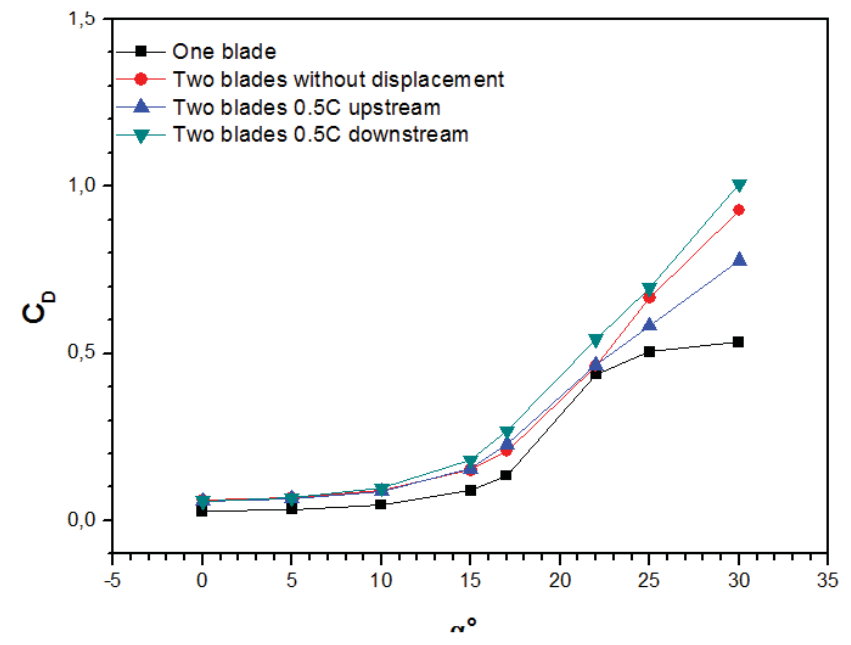

Figure 6: variation of drag coefficient versus incidence angle

\section{EXPERIMENTAL APPARATUS AND PROCEDURES}

\section{Wind tunnel and the Darrieus setups}

The experimental study is conducted in subsonic wind tunnel with closed circuit. The free work section is of square cross-section $0.50 \mathrm{~m} \times 0.50 \mathrm{~m}$ and $0.8 \mathrm{~m}$ long. The velocity could reach $30 \mathrm{~m} / \mathrm{s}$ and the turbulence intensity is less than $1 \%$.

All the tested wind turbines are built in wood, with a height of $40 \mathrm{~cm}$, an outer diameter of $40 \mathrm{~cm}$. The used profile is a NACA 0018 having a chord of $6 \mathrm{~cm}$.

The experiments have been carried firstly on the classical design: the two-bladed Darrieus wind turbine (Figure 9.a), the three (Figure 9.b) and four blades (Figure 9.c) and secondly on three new geometries which have been designed:

- The first geometry consists in arranging each opposed pair of blades in a given radius orbit and

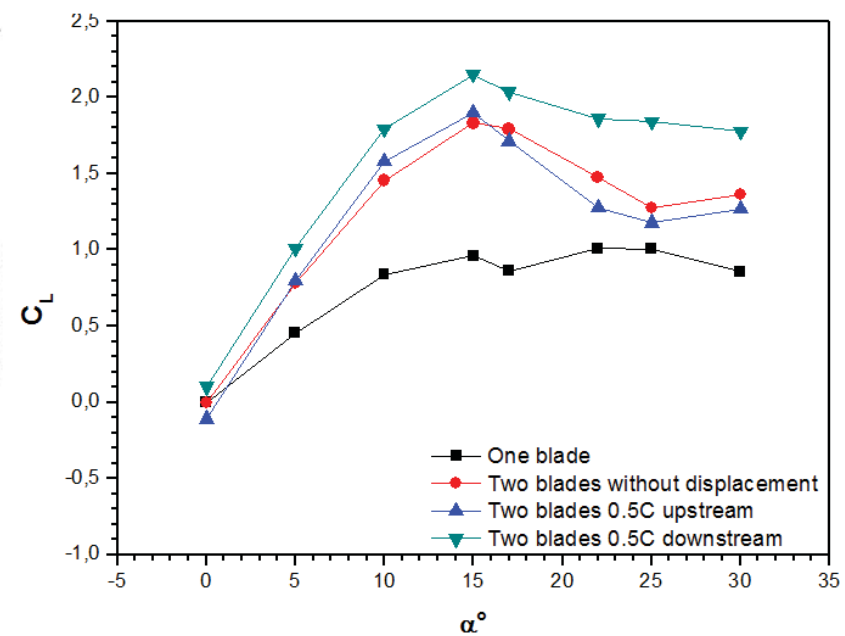

Figure 5: variation of lift coefficient versus incidence angle

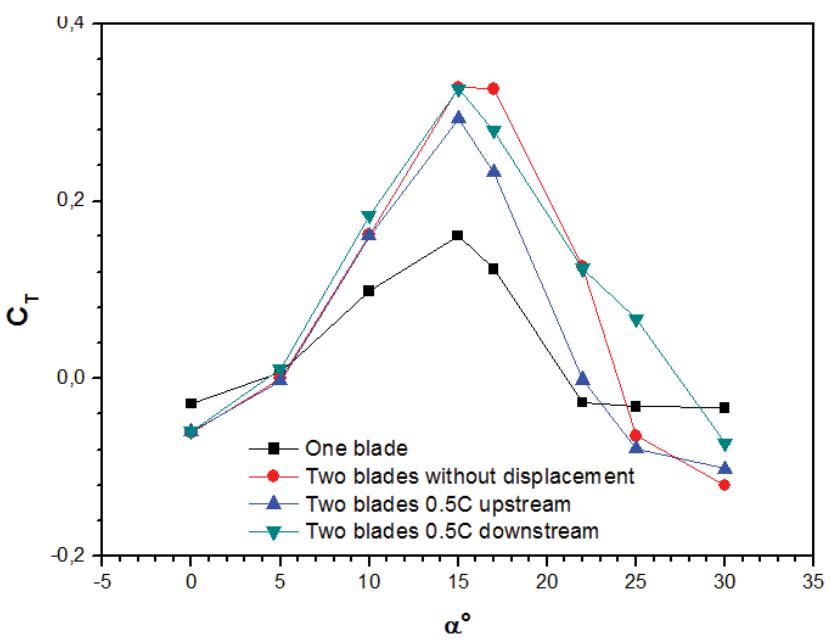

Figure 7: Variation of tangential coefficient versus incidence angle

bringing them closer to form a biplane blades (Figure 7.b). The inner blades are shifted tangentially from the outer blades and for the present work two positions are respectively selected; 0.5 chord downstream (named 0.5C downstream) and 0.5chord upstream (named 0.5C upstream). (Figure 10.a).

- Staggered four blades: where two opposed blades are placed at $\mathrm{R}=20 \mathrm{~cm}$ and the remained opposed blades are displaced at $\mathrm{R}=14 \mathrm{~cm}$ (Figure.10.c).

- Three biplane blades $(3 \times 2)$ : where the inner blades are placed at $R=14 \mathrm{~cm}$ shifted tangentially from the outer blades with 0.5 chord upstream (Figure.10.d). 


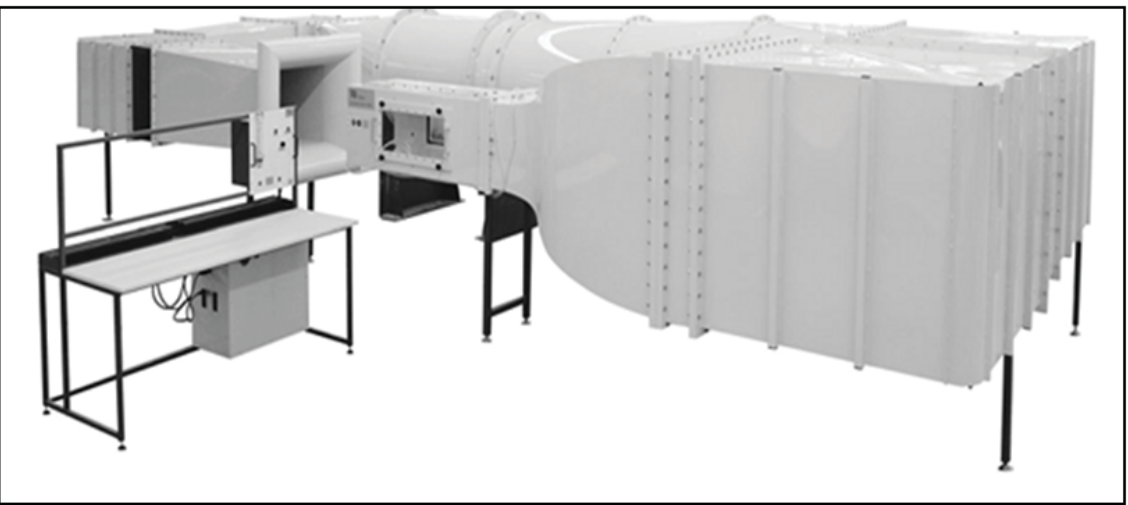

Figure 8: Subsonic wind tunnel TE44

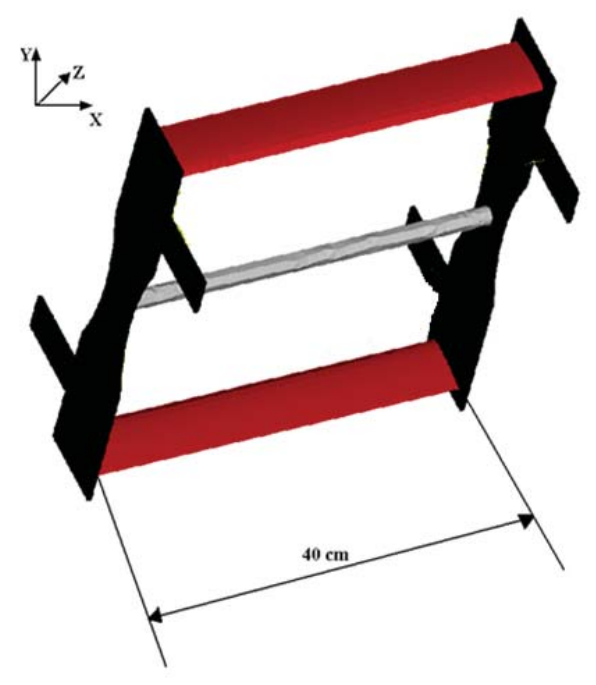

a) Two bladed Darrieus wind turbine

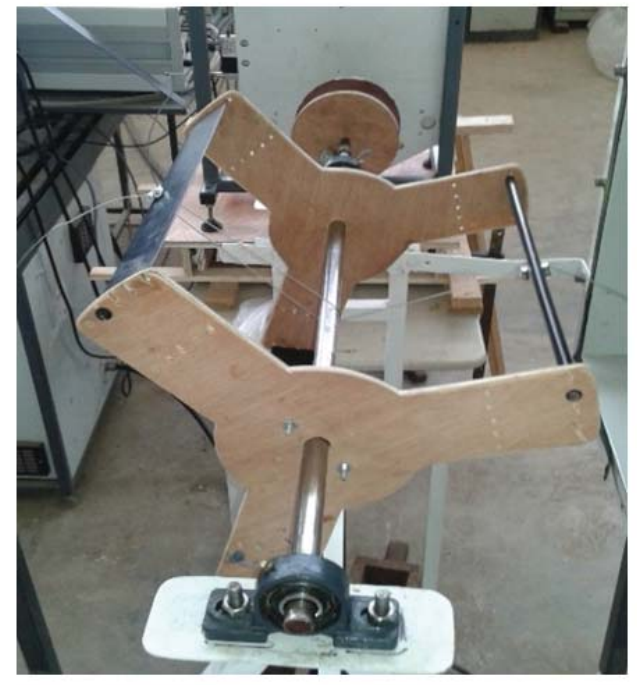

b) Three bladed Darrieus turbine

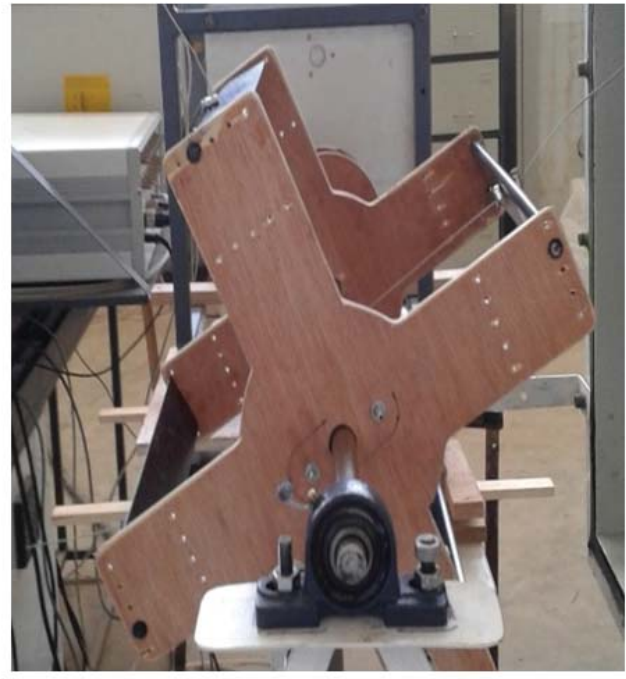

c) Four bladed Darrieus turbine

Figure 9: Classical Darieus wind turbine 


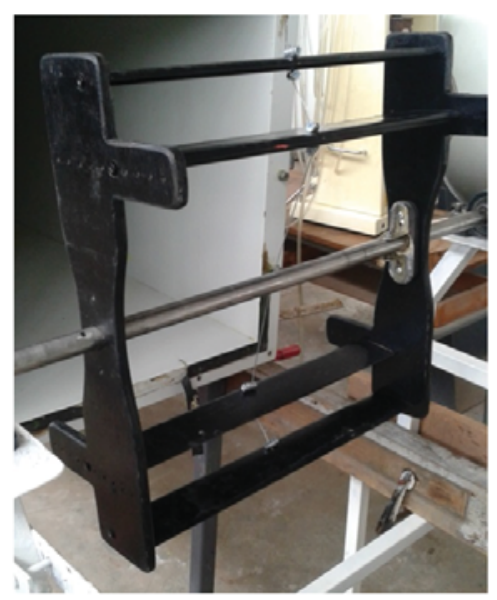

b) $0.5 C$ upstream Darrieus turbine

a) Schematic diagram of new configuration Darrieus turbine $0.5 \mathrm{C}$

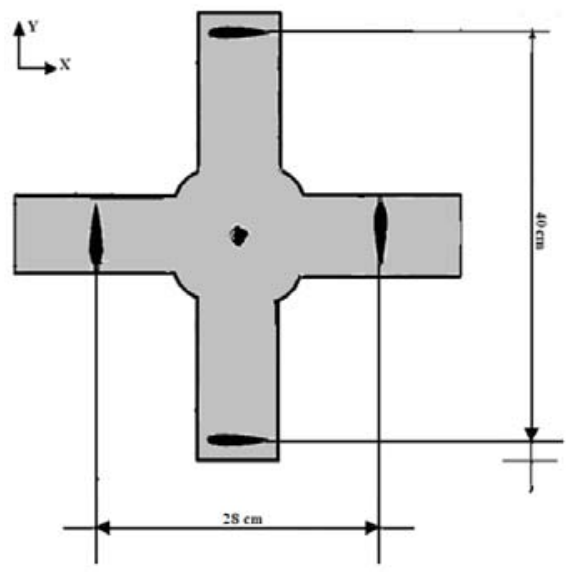

c) Staggered four bladed Darrieus turbine

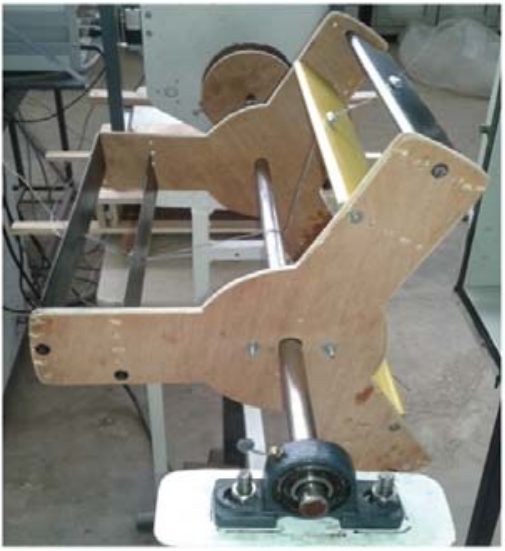

d) Tandem three bladed Darrieus turbine

Figure 10: New Darieus wind turbine configurations

The wind tunnel velocity is determined by using Pitot tube linked to the differential pressure with a multi-channel scanner with an absolute error of $\pm 0.1 \mathrm{~m} / \mathrm{s}$. Measurement of drag and lift forces for the first tests of the isolated tandem blades has been carried out by using a combined wire-strain gauge balance (TE81). The same balance is used to determinate the torque of the wind turbines according to Prony brake method, the absolute error is $\pm 0.05 \mathrm{~N} . \mathrm{m}$. The rotational velocity of the wind turbine is determined using an accurate tachometer contact with an absolute error of $\pm 3 \mathrm{tr} / \mathrm{mn}$. The display unit links to a computer, loaded with software for data analysis and logging of the results.

\section{RESULTS AND DISCUSSION}

According to the dimensions of the wind tunnel work section that was used for testing the Darrieus turbine, the size of this latter is limited, in particular its radius which is only $0.2 \mathrm{~m}$. The different tested configurations lead to study the aerodynamic behavior where only a portion of a standard specific velocities interval (which is from 0 to 7 ) was explored. Indeed, in the present study, the largest specific velocity recorded in the tests is around 2 . Mainly this is due to the low value of wind turbine radius.

Consequently, and since presented investigation in this paper is a comparison of the aerodynamic performance of the proposed designs, two types of tests were selected:

1. The test without charging wind turbine which is to measure the rotational velocity according to the wind velocity of the wind tunnel. In this case, the load applied to the turbine is limited to the friction torque of rolling bearings, considered very low. This test allows to appreciate the power of the machine indirectly through its kinetic energy.

2. The measurement of static torque of the machine, using Prony brake principle. The measured torque permits to appreciate the power of the machine also through its potential energy. 
It is to note that for these two tests the speed of the wind tunnel has been limited about $20 \mathrm{~m} / \mathrm{s}$.

The respective measurements of the rotational speed and the static torque were performed firstly for three standard Darrieus wind turbines, namely in the circumstances; the two-blade, three bladed, the four-bladed and staggered four-bladed. Figure 11 shows the results of the test as a graph where a slight superiority of the four-bladed, which is rotating faster than the other, followed by the staggered four-bladed and the three bladed. It is clear that the rotational speed increases with increasing wind speed and more probably with the number of blades.

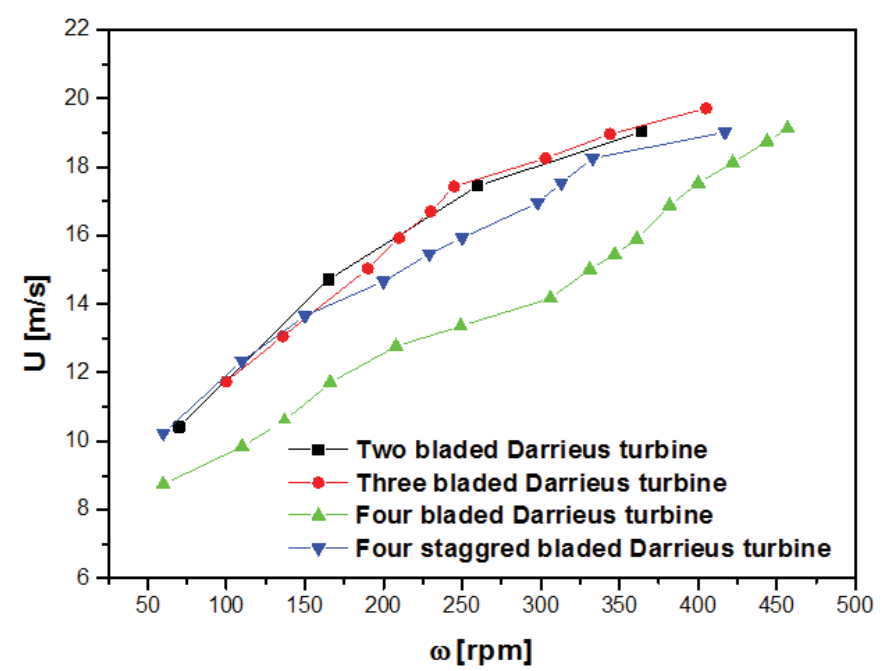

Figure 11: Variation of wind velocity versus rotational speed for classical designs

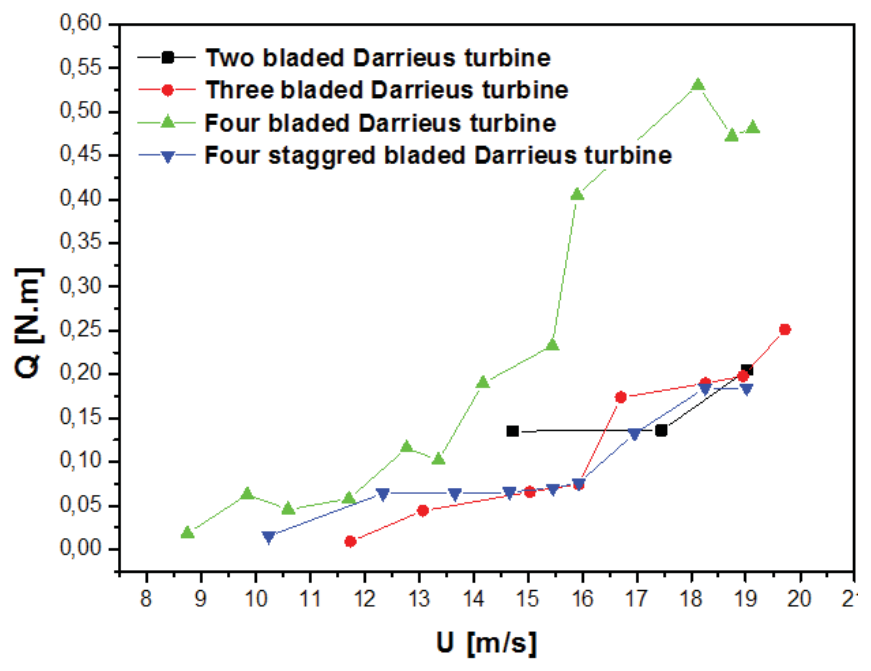

Figure 12: Variation of torque versus wind velocity for classical designs
The effect of the interaction of the wind turbine blades was firstly studied on the staggered four-bladed configuration in approaching the blades together so as to form biplane blades while keeping a constant radial distance. For the three tangential offsets selected, only two of them were actually tested, namely upstream and downstream while tests on the third case have been abandoned because its self - starting requires a much higher wind tunnel velocity. Figures 13 and 14 show the test results without load for the both tested configurations. The superiority of the upstream version is noted, significantly more powerful than the downstream version. It is also less efficient than the two-bladed.

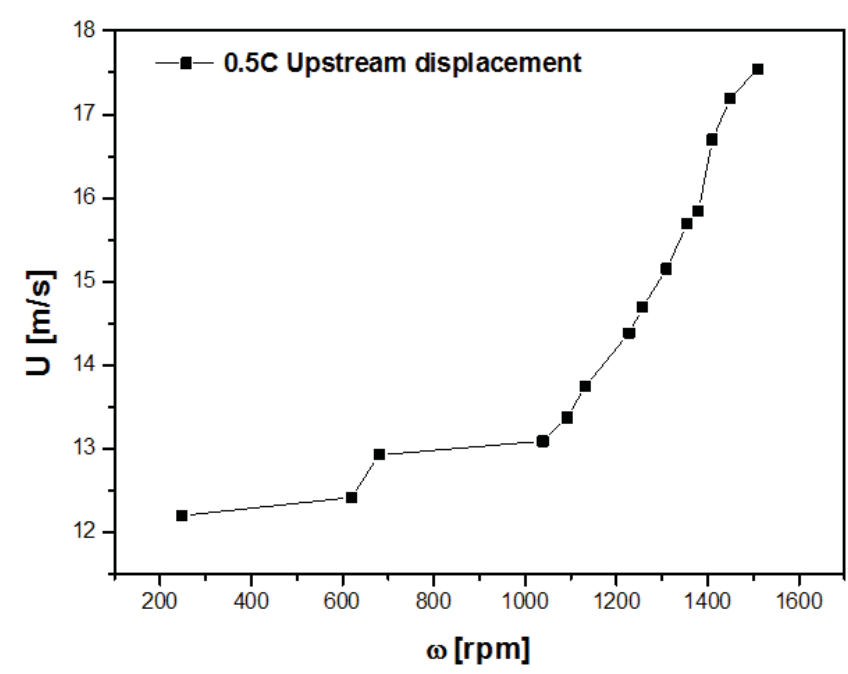

Figure 13: Variation of wind velocity versus rotational speed for the 0.5C upstream displacement

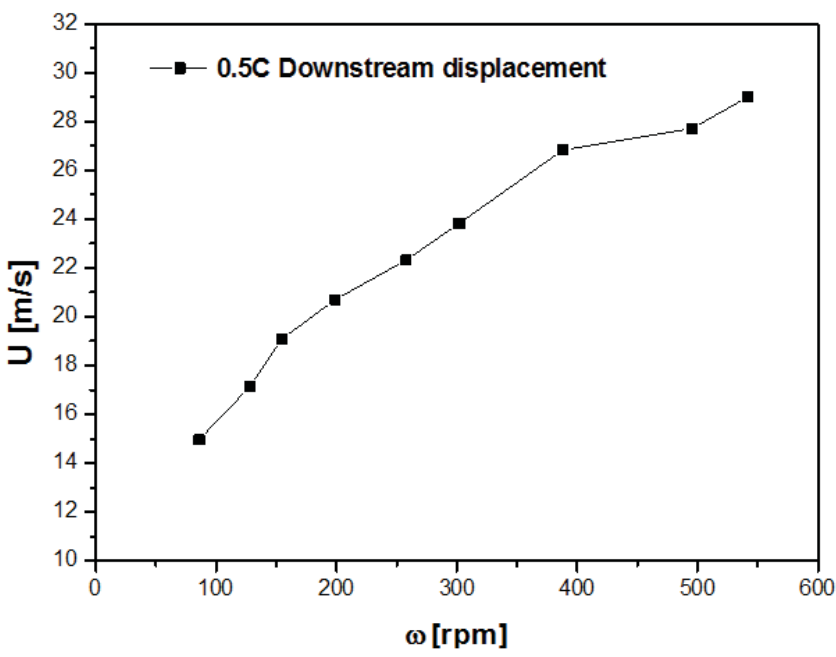

Figure 14: Variation of wind velocity versus rotational speed for the $0.5 \mathrm{C}$ downstream displacement 
Figure 15 illustrates the gap in performance, very important and growing with the increasing of the wind velocity, between the upstream version, classic four-bladed and staggered four-bladed. As can be seen, in tandem, it is clear that the relative position of a blade with respect to each other influences the flow around the machine and thus significantly affects the aerodynamic performance of the latter. Figure 16 shows the evolution of the static torque for these three configurations depending on the wind tunnel velocity. It should be noted, first of all, the growth of torque with the speed which is quite expected. In addition, this test confirms the superiority of the upstream version compared with the other machine but with a slightly higher start torque.

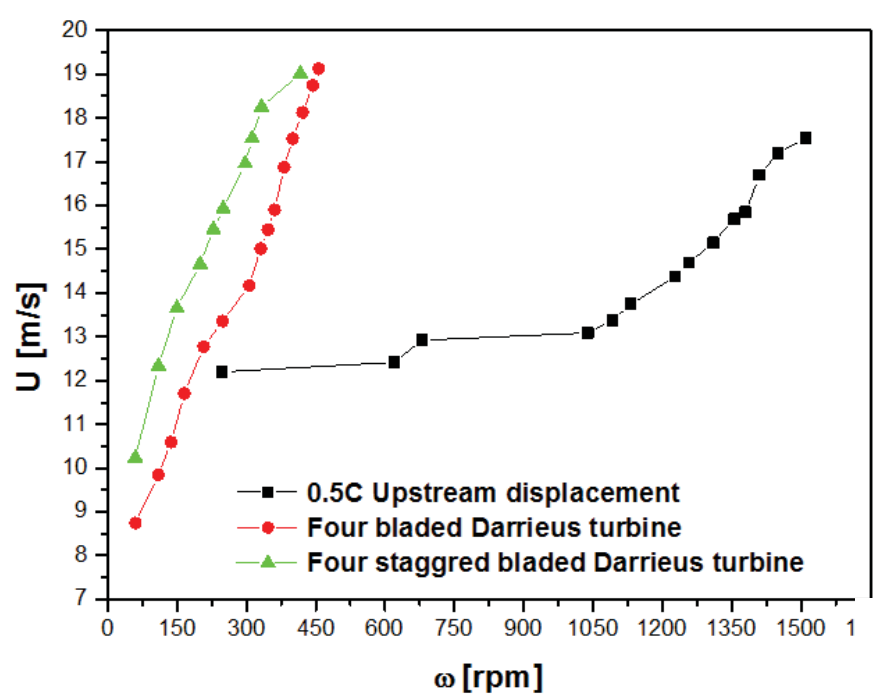

Figure 15: Variation of wind velocity versus rotational speed for the : (a) the upstream version,

(b) classic four-bladed and (c) staggered four-bladed

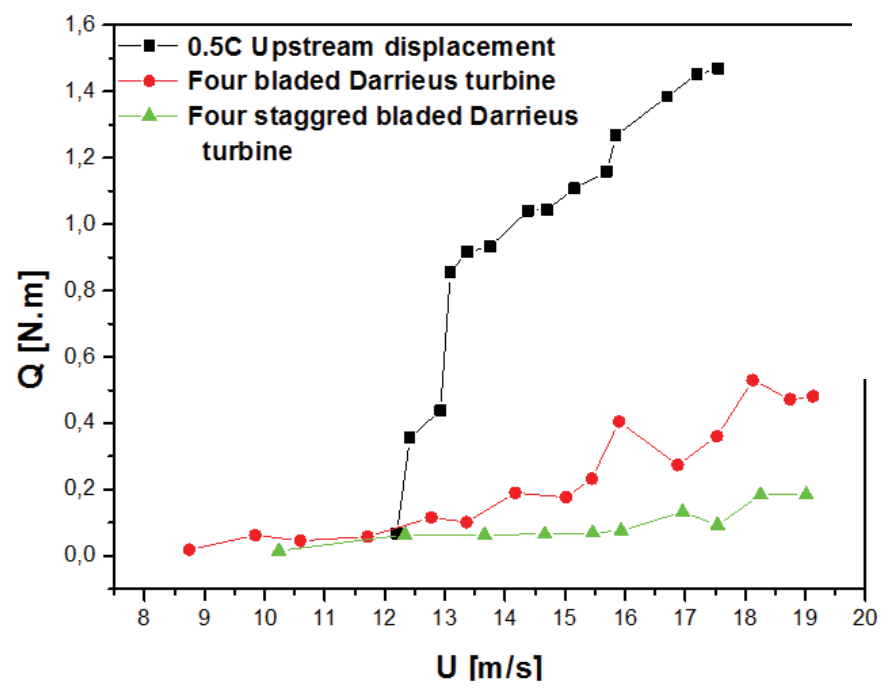

Figure 16: Variation of torque versus wind velocity for the: (a) the upstream version, (b) classic four-bladed and (c) staggered four-bladed
The same tangential shift has been applied to the three-bladed configuration and the results of velocity and static torque measurements indicates that this version is more powerful than the standard three-blade machine as shown in Figures 17 and 18. However, a comparison of the performance of this machine with upstream version shows that it is largely superior.

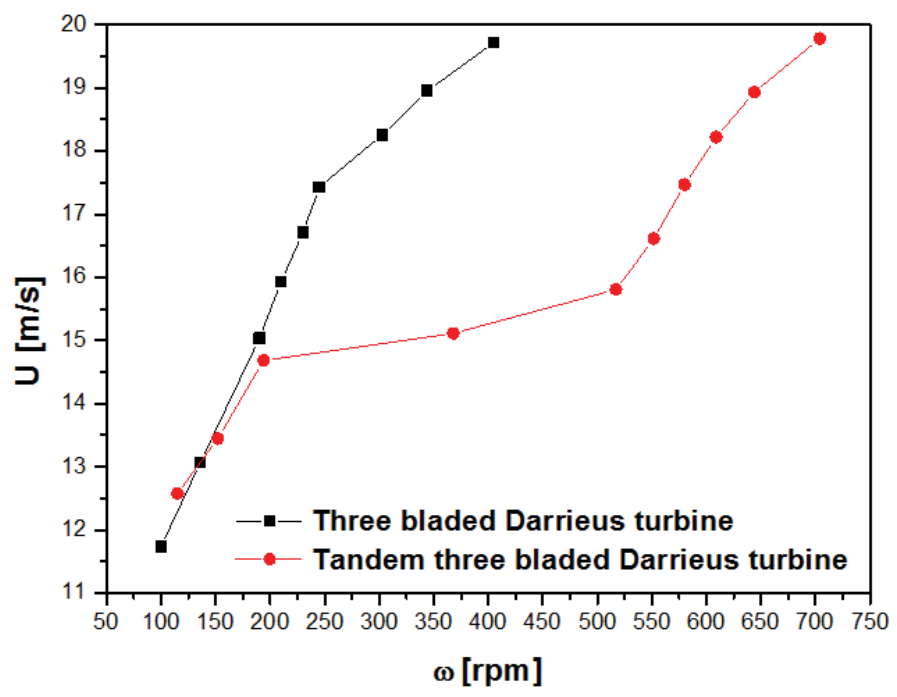

Figure 17: Variation of wind velocity versus rotational speed for the: (a) three bladed and

(b) tandem three bladed

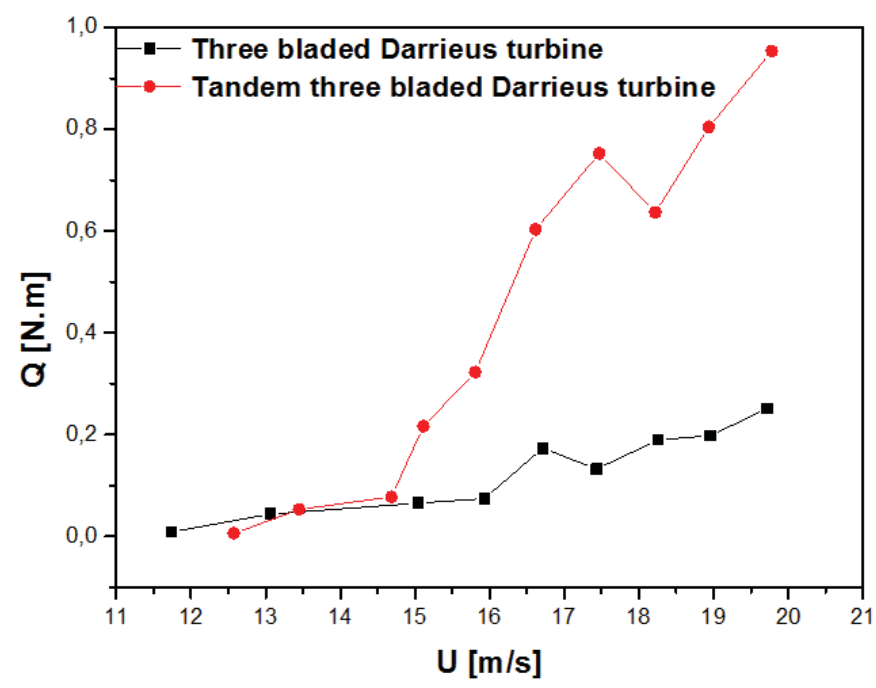

Figure 18: Variation of torque versus wind velocity for the: (a) three bladed and (b) tandem three bladed 


\section{CONCLUSION}

Wind turbine models have been tested in the wind tunnel at a velocity range barely exceeding $20 \mathrm{~m} / \mathrm{s}$ and limiting the TSR less than 2. Two types of test were performed; testing the unloaded machine and the static torque measurement. Both tests were used to characterize these turbines the aerodynamic performance perspective. It is found that the use of tandem blades significantly increases the power of the machines compared with the standard wind turbine, in particular, upstream version that appears to have a very important potential power. To confirm these results it is essential to conduct this type of wind turbine tests for a much larger scale and throughout velocity range where evolve the Darrieus wind turbines.

\section{ACKNOWLEDGMENT}

This contribution has been supported by project No. LO1408 "AdMaS UP - Advanced Materials, Structures and Technologies", supported by Ministry of Education, Youth and Sports Czech Republic under the "National Sustainability Programme I".

\section{REFERENCES}

1. McLaren K. A, "numerical and experimental study of unsteady loading of high solidity vertical axis wind turbines," Ph.D. dissertation, Dept. Mech. Eng., McMaster University, 2011.

2. Marco R.Castelli, A.Englaro, E.Benini, "The Darrieus wind turbine: proposal for a new performance prediction model based on CFD," Energy, 36, 20 May 2011.

3. Marco R.Castelli, S. De Betta and E. Benini, "Effect of Blade Number on a Straight-Bladed Vertical-Axis Darreius Wind Turbine,"World Academy of Science Engineering and Technology", 61, 2012.

4. Robert Howell, N.Qin, J.Edwards, N.Durrani, "wind tunnel and numerical study of a small vertical axis wind turbine," Renewable energy, 35, 2010.

5. Taher G, A.M.ali, M. Al-Ajmi, I.M.Hassan, "Effect of number of blades and blade chord length on the performance of Darrieus wind turbine," American journal of mechanical engineering and automation, pp.16-25, 2015.

6. Md Farhad Ismail, Krishna Vijayaraghavan, "The effects of aerofoil profile modification on a vertical axis wind turbine performance," Energy, 80, 2015.

7. M.H.Mohamed, A.M.Ali, A.A.Hafiz, "CFD analysis for $\mathrm{H}$-rotor Darrieus turbine as a low speed wind energy converter," Engineering science and technology an international journal, 18, 2015.

8. Arti Tirkey, Yamini Sarthi, K.Patel, R.Sharma, P.K.Sen, "study on the effect of blade profile, number blade, Reynolds number aspect ratio on the performance of vertical axis wind turbine," International journal of science engineering and technology research, vol 3,issue 12, December 2014.

9. Payam Sabaeifard, H.Razzaghi, A.Forouzandeh, "Determination of vertical axis wind turbine optimal configuration through CFD simulations", Proc. International conference on future environment and energy IPCBEE, IACSIT Press, Singapoore, 2012, vol.28.

10. Taher G.Abu-El-Yazied, Hossam N.Doghiem, Ahmed M.Ali, Islam M.Hassan, "Investigation of the aerodynamic performance of Darrieus vertical axis wind turbine," IOSR journal of engineering, Vol.04, issue 05, May 2014.

11. L.A. Danao, J.Edwards, O.Eboibi, R. Howell, "A numerical investigation into the influence of unsteady wind on the performance and aerodynamics of a vertical axis wind turbine," Appl. Energy, 116, pp. 111-124, 2014.

12. K.M. Almohammadi, D.B. Ingham, Ma.L. Pourkashan, "Computational fluid dynamics (CFD) mesh independency techniques for a straight blade vertical axis wind turbine," Energy 58,pp.483-49, 2013.

13. R.Nobile, M.Vahdati, J.F.Barlow, A. Mewburn-Crook, "Unsteady flow simulation of a vertical axis augmented wind turbine: a two-dimensional study," J. Wind Eng. Ind. Aerodyn.125, pp.168-179, 2014.

14. M. Elkhoury , T.Kiwata , E.Aoun, "Experimental and numerical investigation of a three-dimensional vertical-axis wind turbine with variable-pitch,".J.WindEng.Ind.Aerodyn.139, pp.111-123, 2015.

15. M.Samanoudy-EI, AAE. Ghorab, SZ.Youssef, "Effect of some design parameters on the performance of a Giromill vertical axis wind turbine," Ain Shams Eng J Elsevier, Vol 1, pp. 85-95, 2010.

16. M.A. Singh, Biswas, R.D. Misra, "Investigation of self-starting and high rotor solidity on the performance of a three $\mathrm{S} 1210$ blade H-type Darrieus rotor," Renewable Energy, 76, pp. 381-387, 2015.

17. A.M. Cismilianu, A. Boros, I.C. Oncescu, F. Frunzulica, "New Urban Vertical Axis Wind Turbine Design," INCAS BULLETIN, Vol 7, Issue 4, pp. 67

Paper submitted: 30.08.2017.

Paper accepted: 28.11.2017.

This is an open access article distributed under the CC BY-NC-ND 4.0 terms and conditions. 